\title{
Seasonal Variation of Pinatubo Volcanic Aerosols in the Stratosphere Observed by Lidar in Fukuoka
}

\author{
Motoaki YASUI ${ }^{1}$, Motowo FUJWARA ${ }^{2}$, Hideharu AKIYOSHI ${ }^{2}$, Seiji IKAWA ${ }^{2}$, \\ Hidefumi NONAKA ${ }^{2}$, and Koichi SHIRAISHI ${ }^{2}$ \\ ${ }^{1}$ Department of Earth and Planetary Science, Kyushu University, Fukuoka 812, Japan \\ ${ }^{2}$ Department of Applied Physics, Fukuoka University, Fukuoka 814-01, Japan
}

(Received December 17, 1994; Revised August 20, 1995; Accepted August 29, 1995)

\begin{abstract}
Stratospheric aerosols originating from the June 1991 explosive eruptions of Mt. Pinatubo has been observed at Fukuoka with a Nd:YAG lidar. Sudden increase of the aerosols in the vicinity just above the tropopause in July 1991 was followed by the appearance of extraordinary strong scattering layer around 21-22 km height. The volcanic aerosols stratified in two distinct layers merged into a broad layer when the background wind field changed from the easterlies to the westerlies and the bulk of the aerosols arrived. After having taken its maximum in the first winter the aerosol burden decreased monotonously. Superposed on the decrease we can read the seasonal variations associated with the seasonal variation in the wind field and the tropopause height also after the second year.

Height of the center of gravity of the aerosols relative to the height of tropopause have been approaching gradually to a constant value.
\end{abstract}

\section{Introduction}

Violent enuptions of Mt. Pinatubo in Philippines $\left(15.1^{\circ} \mathrm{N}, 120.4^{\circ} \mathrm{E}\right)$ injected a large amount of volcanic gasses and other effluents into the atmosphere and caused a serious perturbation on the stratospheric aerosols globally. The amount of $\mathrm{SO}_{2}$ gas injected into the stratosphere have been estimated to be much more than that produced by the eruptions of El Chichón in 1982 (McCormick and Veiga, 1992; Bluth et al., 1992; McPeters, 1993; Strong et al., 1993). Sudden and extraordinary increase of the stratospheric aerosols have been detected by satellite (McCormick and Veiga, 1992) and lidar, both airborne and ground-based (DeFoor et al., 1992; Gobbi et al., 1992; Jäger, 1992; Hayashida and Sasano, 1993; Uchino et al., 1993).

Volcanic aerosols dispersed in the stratosphere give a significant effect not only on the global climate through their absorption and scattering of radiation but also on the chemical processes in the stratosphere such as the ozone depletion through the heterogeneous reactions on their surfaces (Xue et al., 1994; Hofmann and Solomon, 1989).

Using a Nd:YAG lidar system, a scattering layer, a trace of the Pinatubo volcanic aerosols, was observed just above the tropopause over Fukuoka $\left(33^{\circ} \mathrm{N}, 135^{\circ} \mathrm{E}\right)$ first on July 7 , about 3 weeks after the major eruptions of Pinatubo on June 15, 1991. The bulk of the volcanic aerosol layer around the altitudes of $21 \mathrm{~km}$ arrived about two months later and the layer have persisted for more than three years having been decreasing its concentration.

Variation of the volcanic aerosols for about 1000 days from the first detection over Fukuoka will be presented $\mathrm{m}$ this paper especially from the viewpoint of seasonal variations.

\section{Observation and Analysis}

\subsection{Instruments}

At Fukuoka University a small Nd:YAG lidar system had been operated to probe mainly the 
tropospheric aerosols. When the Pinatubo volcanic aerosols arrived in the stratosphere over Japan, a multichannel analyzer was equipped to the lidar system for the photon counting and we started the observation of me stratosphere in the early June, 1991. The specifications of the lidar system are shown in Table 1.

\subsection{Calculations of backscattering coefficient and scattering ratio of the aerosols}

Backscattering coefficients of the aerosols were calculated from me lidar return signals with the local meteorological data which were supplied by Fukuoka Meteorological Observatory. In these calculation, Fernald's method (Fernald, 1984) has been applied under the assumption that $S$-parameter, the ratio of backscattering to extinction coefficients of the aerosols, is constant with height. Considering the variability in the optical properties of aerosols with time, we adopted some different values of $S$-parameter for different periods. Values used in the present analysis which were supplied by Meteorological Research Institute are listed on Table 2.

From the backscattering coefficient of aerosols $\beta_{\mathrm{a}}(z)$ and atmospheric molecules $\beta_{\mathrm{m}}(z)$ the scattering ratio of aerosols $R(z)$ is defined as follows:

$$
R(z)=\frac{\beta_{\mathrm{a}}(z)+\beta_{\mathrm{m}}(z)}{\beta_{\mathrm{m}}(z)}
$$

\subsection{Determination of the lower boundary of stratospheric aerosols}

In order to discuss the stratospheric aerosols, it is important to determine a lower boundary of the stratospheric aerosol layer properly. Usually, tropopause, which is defined as the height at which the vertical gradient of temperature exceeds a certain value, is considered to be the boundary. In some occasion, however, some problems arise if we use the tropopause as the boundary. Figure 1 shows an

Table 1. Specifications of lidar in Fukuoka University.

(1) transmitting system

laser

wave length

Nd:YAG laser

power

pulse width

$532 \mathrm{~nm}$

$100 \mathrm{~mJ} /$ pulse

repetition

$7 \mathrm{~ns}$

collimator

$10 \mathrm{~Hz}$

$10 \mathrm{~cm}$ diameter telescope

(2) Detecting system

telescope

$30 \mathrm{~cm}$ diameter (Cassegrain type)

filter

$532 \mathrm{~nm}$ narrow band pass interference filter (FWHM: $1.7 \mathrm{~nm}$ )

photo multiplier EMI 9558QB

photon counter

Multi Channel Analyzer divide a signal into 1024 channels and count the number of photons within each channel ( 1 channel $=1$ micro sec.)

Table 2. S-Parameters used in the analysis.

\begin{tabular}{lc}
\hline \multicolumn{1}{c}{ Period } & $S$-parameter (Sr) \\
\hline Jun. 1, 1991 Nov. 30, 1991 & 50 \\
Dec. 1, 1991 Jan. 31, 1992 & 45 \\
Feb. 1, 1992 Dec. 1, 1992 & 40 \\
Dec. 2, 1992 & 35 \\
\hline
\end{tabular}


example of the tropopause which does not seem to determine the lower boundary of the stratospheric aerosol layer. The tropopause, which is drawn by dashed line in the figure, crosses the middle part of the stratospheric aerosol layer. In this case, if the backscattering coefficient is integrated from the tropopause, the I.B.C. will be underestimated. Furthermore, in some occasion, many local tropopauses appear at a time of observation as there often appear several inversions in a temperature profile, especially in winter season. In such occasion, it is difficult to choose one tropopause from one local rawin-sonde data supplied only by Fukuoka Meteorological Observatory. That is why, a farther physical consideration is needed to determine the lower boundary. To do so, we took into account the stability of the atmosphere. From the fact that the atmosphere is much more stable in the stratosphere than in the troposphere, and that the distribution of matter in the atmosphere is affected by the atmospheric stability, we determined the lower boundary of the stratospheric aerosol layer as the transition height of vertical stability. According to the thermodynamical consideration, the vertical gradient of potential temperature is considered to be a better index of the vertical stability of the atmosphere than the temperature gradient. An example of the vertical

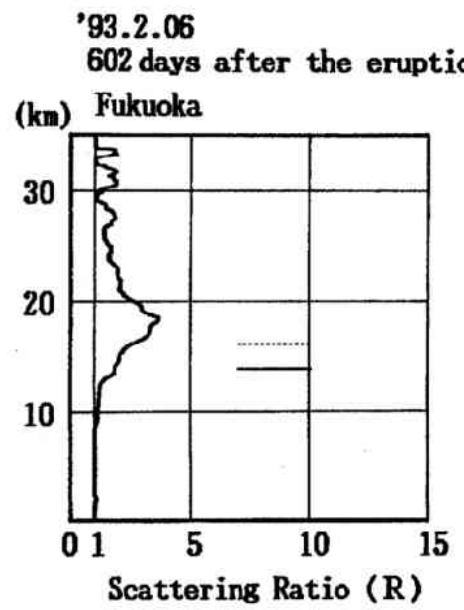

Fig. 1. An example of tropopause (dashed line) which does not determine the lower boundary of the stratospheric aerosol layer properly. Thick line is the lower boundary which determined taking into account the atmospheric stability.

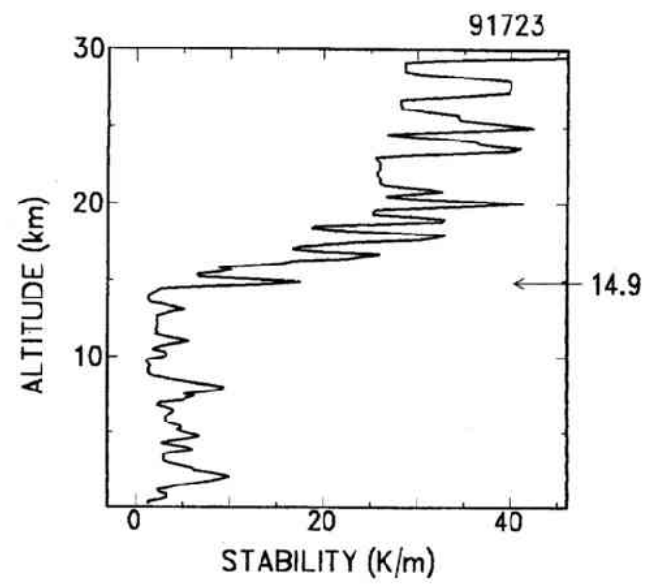

Fig. 2. An example of vertical stability of the atmosphere. Value of the stability jumps at $14.9 \mathrm{~km}$. 
gradient of potential temperature is shown in Fig. 2. Values of the gradient were around $5 \mathrm{~K} / \mathrm{km}$ in the upper troposphere, and around $35 \mathrm{~K} / \mathrm{km}$ in the lower stratosphere. There is a gap at $14.9 \mathrm{~km}$. The gap is a transition height of the vertical stability, and is chosen as a lower boundary of the stratospheric aerosol layer of that day. We used the height of the lower boundary in the calculation of I.B.C. The lower boundary thus determined coincide approximately with the lowest tropopause in many cases, but sometimes not. In Fig. 1 the lower boundary, which is determined by our method described above, is drawn by a thick line. The consistency of the redetermined boundary (thick line) with the profile of the aerosol layer is better than that of the tropopause (dashed line).

\section{Results and Discussion}

\subsection{Variations in the initial stage}

Typical profiles of Pinatubo volcanic aerosols observed in the initial stage are shown in Figs. 3(a)

(a)

'91.7.07

22 days after the eruption

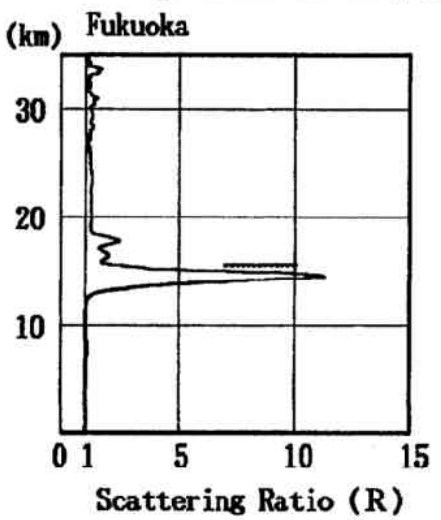

(c)

'92.1.26

225 days after the eruption

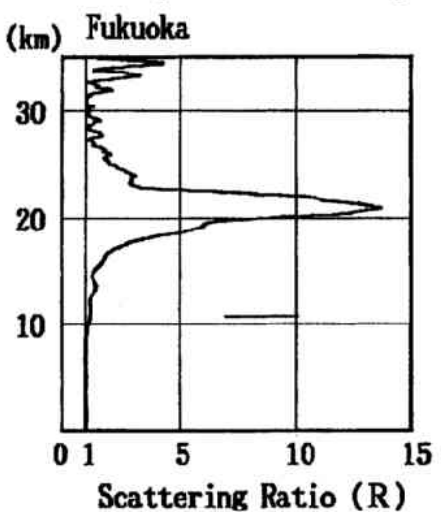

(b)

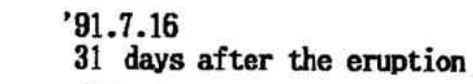

(km) Fukuoka

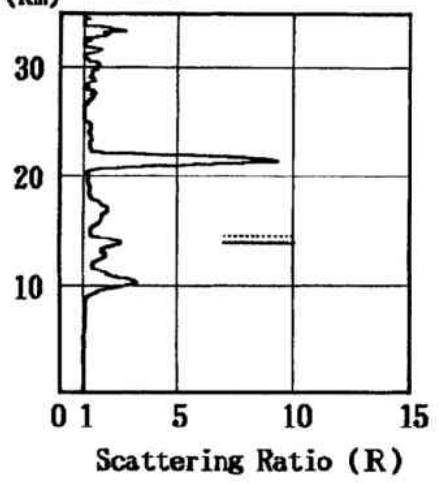

(d)

' 93.10 .23

861 days after the eruption

(km) Fukuoka

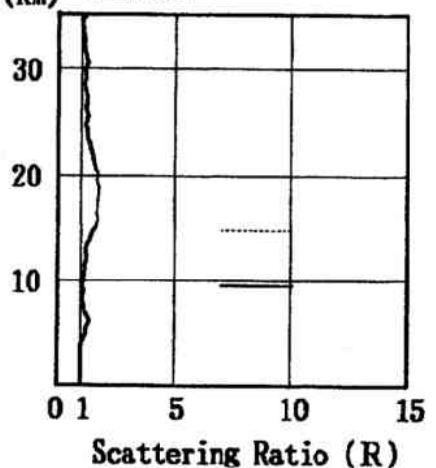

Fig. 3. Typical vertical profiles of scattering ratio. (a) The first scattering layer of Mt. Pinatubo-aerosols observed just above tropopause on July 7 in 1991. (b) An intense scattering ratio observed around $21 \mathrm{~km}$ on July 16 in 1991. (c) Large value of scatteling ratio observed in the first winter. (The lower boundary coincides with the tropopause.) (d) One of the scattering ratios observed in the third ycar. 
and 3(b). A significant layer of the aerosols was observed just above the tropopause (17-18 km) over Fukuoka at the first sounding of the improved lidar system, on July 7,1991 . The date of the first detection, however, does not mean the date of arrival of the first Pinatubo cloud as it had been observed more than a week before at the stations of higher latitudes in Japan (Hayashida and Sasano, 1993; Uchinoet al., 1993).

On July 16, 1991 much stronger scattering layer appeared at 21-22 km height, and the scattering ratio was about 9 . After then this upper layer appeared intermittently mainly at $21-22 \mathrm{~km}$ height, more appropriately around the height of the potential temperature of $520 \mathrm{~K}$, while the lower layer almost always appeared around the height of $400 \mathrm{~K}$ until a bulk of the upper layer arrived, and they merged into one enormous layer in September of the year.

In the paper by Hayashida and Sasano (1993) results of the lidar observation in Tsukuba $\left(36^{\circ} \mathrm{N}\right)$ are reported, and Jäger (1992) reported results obtained in Garmisch-Partenkirchen $\left(47.5^{\circ} \mathrm{N}\right)$ in Germany. In Tsukuba (Hayashida and Sasano, 1993), the first arrival of the Pinatubo aerosol layer which appeared just above the local tropopause was on June 28, and another layer appeared at higher altitude, around 21 to 22 $\mathrm{km}$, in mid July. In the case of the observation in Garmisch-Partenkirchen (Jäger), the first arrival was on July 1 which was close to the first arrival of the layer $m$ Tsukuba, but the arrival of the layer at higher altitude was in August, about one month later than the arrival in Tsukuba.

In Fukuoka, the first detection of the volcanic scattering layer was just above the lower boundary on July 7 , but it is not clear whether the first arrival of the layer coincides with the first detection or not, as

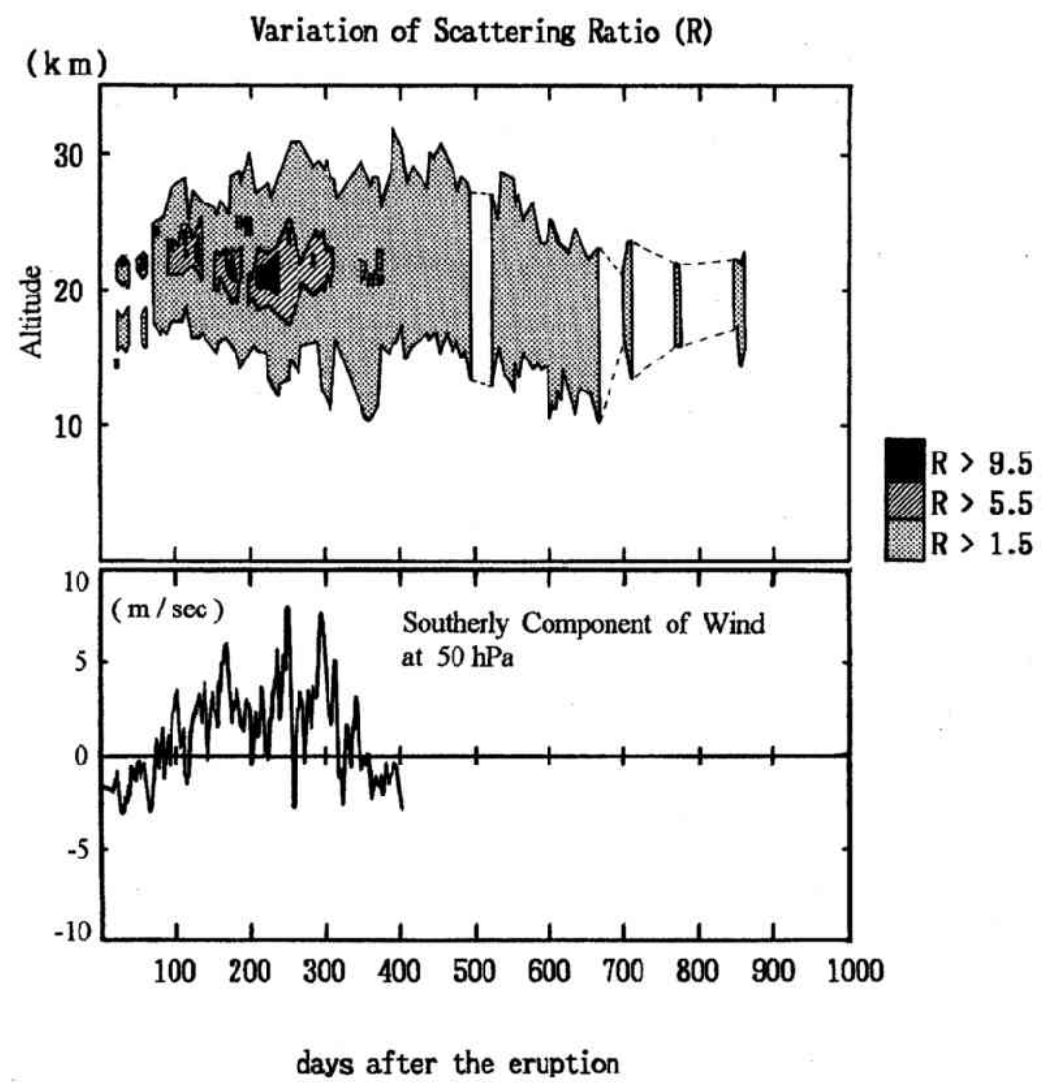

Fig. 4. Time-height cross section of scattering ratio. Bulk of the Pinatubo volcanic aerosol layer appeared in the first autumn after the eruption of Mt. Pinatubo. Extremely intense scattering ratios were often observed in the first year. The layer $(R>1.5)$ had persisted more than three years. Variation of southerly component of wind at $50 \mathrm{hPa}$ during is shown in the lower part of the figure. Large values of scattering ratios were observed when the southerly component was enhanced. 
the observation in Fukuoka started on July 6. Upper layer of the volcanic aerosols, which appeared around 21 to $22 \mathrm{~km}$, was observed on July 16 for the first time. After the day, those two of the distinct layers had been observed frequently until they were merged into a main layer in late September. The main layer was centered around 21 to $22 \mathrm{~km}$, and spread in a wide altitude range from just above the lower boundary up to around $25 \mathrm{~km}$. Although the individual dates of appearance and disappearance, and the values of scattering ratio of both layers are different at two stations in the initial stage when the volcanic aerosols were inhomogeneous along the latitudinal circles, the long term behavior of those layers shows quite similar pattern. That is, they are characterized by appearance of the first layer just above the lower boundary in late June to early July, the upper layer around 21 to $22 \mathrm{~km}$ in mid July and the main broad layer in late September.

In spite of the difference in the latitudes, the days of the appearance of the first layer in Japan and Germany were close, in late June to early July. While, the upper layer appeared over Germany about one month later than Japan. From these results, it is supposed that some fast transport of the volcanic aerosols to higher latitudes occurred around the altitude just above the lower boundary, and the upper layer was transported slowly to the higher latitudes.

The time-height cross section and time variability of the peak values of the scattering ratios are shown, respectively in Figs. 4 and 5. Detailed examination of these figures shows that extremely large scattering ratios were observed every about one month during the first year. Compared with the southerly and westerly components of wind at $50 \mathrm{hPa}$ observed at Fukuoka, respectively shown in Figs. 6(a) and 6(b), each appearance of extremely intense scattering ratio shows better coincidence with the enhancement of the southerly component than with the westerly component. Large fluctuations of the scattering ratio associated with the meandering of the stream line suggested strong inhomogeneity in the latitudinal distribution of the volcanic aerosols.

To examine the correlation of the appearances of large scattering ratios with the southerly component of wind in more detail, peak values of the scattering ratios and velocities of the southerly components of wind at $50 \mathrm{hPa}$ are plotted in Fig. $7.81 \%$ of the peaks which exceeded 5.5 were appeared when the southern

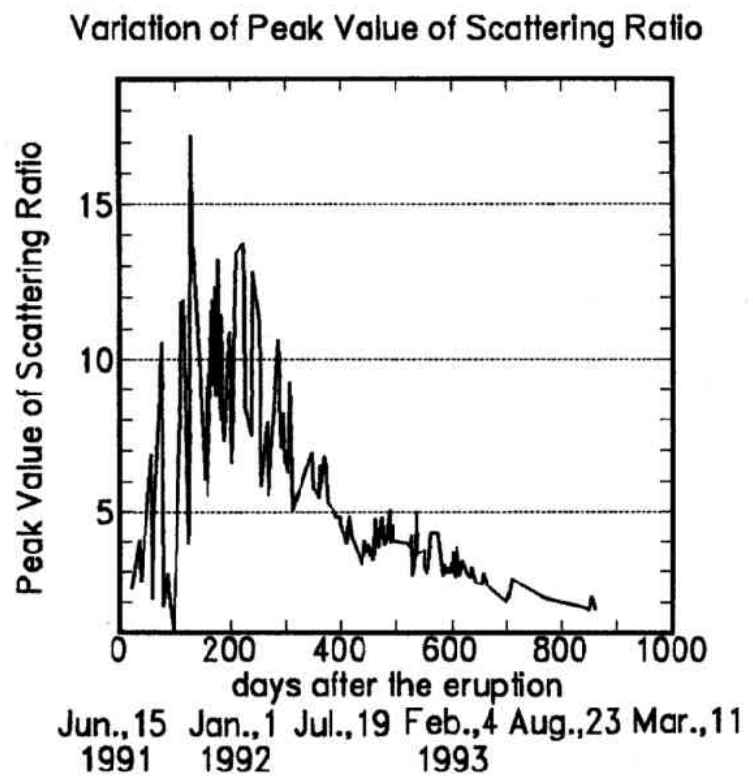

Fig. 5. Variation of peak values of scattering ratios. 
components of the winds were positive, and on the whole, the peak values are showing a trend of increasing with the southerly components of the winds. The good correlation of the appearance of large scattering ratios to the southerly component of the wind is suggesting that the most of the transport of the volcanic aerosols were from the lower latitudes. This means that the belt of the lower latitude circles was a reservoir of the volcanic aerosols and the latitudinal gradient of the density of the volcanic aerosols were large during the first year.

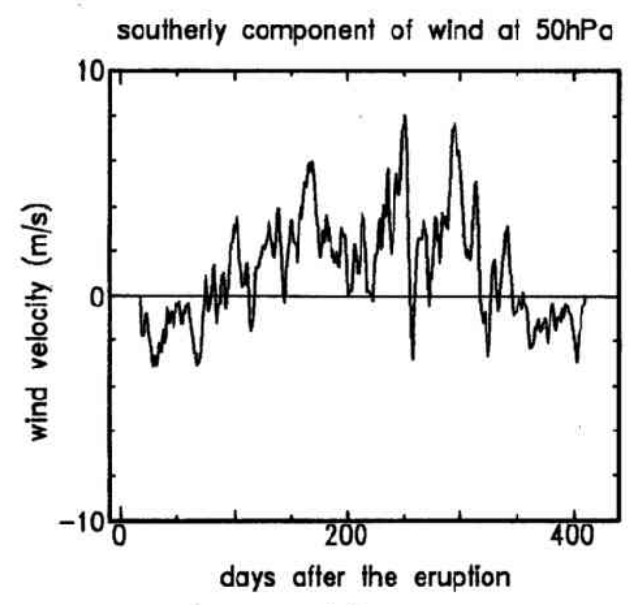

(a)

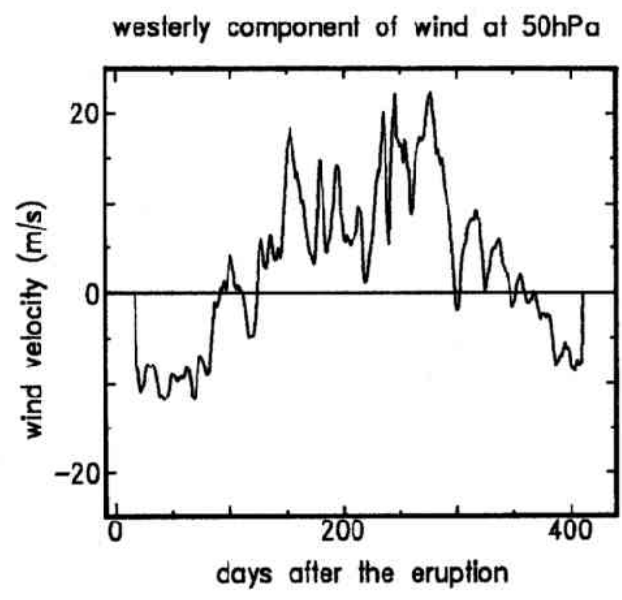

(b)

Fig. 6. (a) Variation of westerly component of wind at $50 \mathrm{hPa}$ over Fukuoka during the first winter. (b) Variation of southern component of the wind.

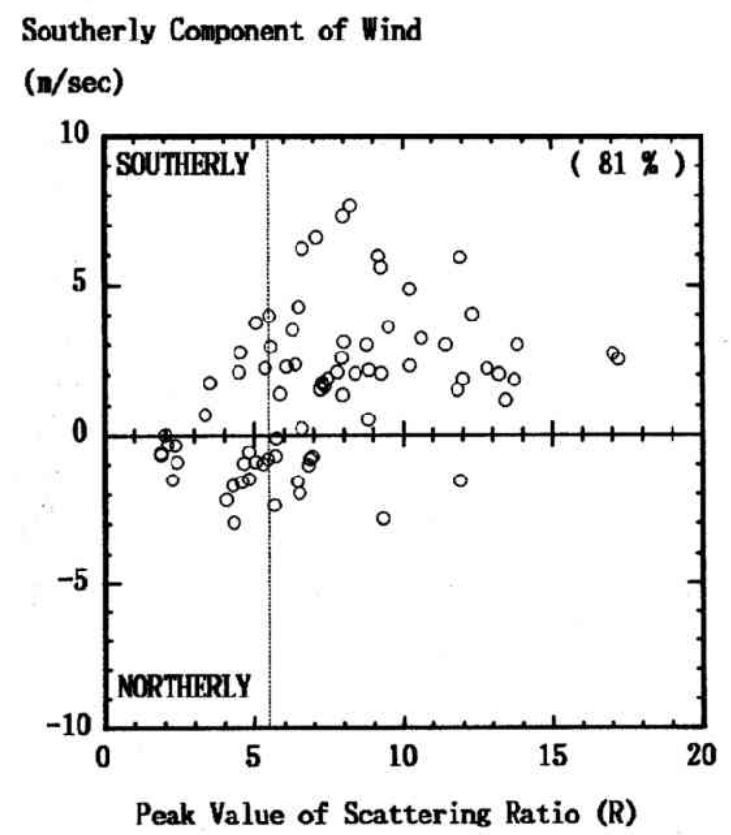

Fig. 7. Correlation between peak value of seattering ratio and southern component of wind at $50 \mathrm{hPa}$. 


\subsection{Seasonal variation}

The bulk of the volcanic aerosols arrived when the westerlies began to prevail in fall. It implies that latitudinal transport of the volcanic aerosols were enhanced in the westerly wind field where the fluctuation of the southerly wind was also large.

Extremely large values of scattering ratio appeared frequently during the period of westerly wind in the first year. An example of the typical profile during the period is shown in Fig. 3(c). In the next year, peaks also appeared frequently in the westerly region but the values were comparatively small. The large latitudinal gradient in the density of volcanic aerosols in the first year should be well relaxed in the next year.

Although the variation of peak scattering ratio in Fig. 5 reveals little seasonal trend after the second year 1992 the variation of integrated backscatteling coefficient, I.B.C., shows obvious seasonal variation. Figure 8 summarizes the I.B.C. integrated over the region from the lower boundary to about $30 \mathrm{~km}$ height. Heights of the tropopause are also shown. I.B.C. attained its maximum in February 1992, more than three months later than the maximum of scattering ratio. During a few months after the eruption of Mt. Pinatubo, relatively dense volcanic aerosols were confined m narrow vertical range, and the peak values of scattering ratios attained its maximum in the early stages. While the vertically integrated amounts of the aerosols were still small in the early period because of the narrow vertical distribution. That is why the attainment of the maximum of I.B.C. delayed as described above. After attaining the maximum, I.B.C. has decreased monotonously. Superposed on the long term monotonous decrease, the I.B.C. shows apparent seasonal variation with maximum in winter and minimum in summer. This variation is associated with the variation of the tropopause height, low in winter and high in summer.

Uchino et al. (1995) observed the variation of the Pinatubo volcanic aerosols by lidars in Tsukuba, Naha, Japan, and Lauder, New Zealand. The I.B.C. attained its maximum in austral winter and minimum in austral summer. Our observation agrees well with their result that the obvious seasonal variations of I.B.C. occur in the whole globe.

Figure 9 is showing the time variability of center of gravity of backscattering coefficient and tropopause height. The variation of the center of gravity was small in the first year. In the second year, the center of gravity varied well corresponding to the variation of the tropopause height. From this trend, it is considered that the initial bulk layer of Mt. Pinatubo aerosols, which located around $21 \mathrm{~km}$, have descended with time and the center of gravity approached the altitudes around a few $\mathrm{km}$ above the tropopause in the second year.

It is impossible to calculate the speed of the gravity sedimentation of aerosols precisely only from the variation of the height of center of gravity as the downward motion of the center of gravity is considered to be a result of complex mechanisms. For instance, height of the lower boundary, which is a sink of the stratospheric aerosols, varies with season, and the center of gravity of the stratospheric aerosol layer varies with the height of tropopause. Moreover, growth rate of the aerosols could have been variable with atmospheric condition which is considered to vary both with time and height.

Here, we discuss about average speed of the downward motion of the center of gravity during a period before the aerosol layer reached local equilibrium state in which the nucleation, evaporation, sedimentation, and vertical and horizontal eddy transport are balanced and the similar seasonal variation are repeated every year. The downward velocity thus determined should be influenced mainly by the additional sedimentation velocity to the equilibrium one.

The center of gravity which located around $19 \mathrm{~km}$ in the first winter descended to the altitudes around $16 \mathrm{~km}$ in the second winter, and the average speed is about $3 \mathrm{~km} /$ year which is converted to about $8.2 \mathrm{~m} /$ day. That is, the center of gravity settled to the equilibrium height at latest in the second winter, and the settling velocity was at least $8.2 \mathrm{~m} /$ day. Incidentally, the terminal velocity of $8.2 \mathrm{~m} /$ day around the altitude of $20 \mathrm{~km}$ reads to the radius of the particle about $0.25 \mu \mathrm{m}$. This result implies that the mean radius of the Pinatubo volcanic aerosols was greater than $0.25 \mu \mathrm{m}$. Russell et al. (1993) estimated the effective radius of the Pinatubo volcanic aerosols using the data obtained by optical methods, and reported that the effectiveradius has grown with time from $0.22 \pm 0.06 \mu \mathrm{m}$ in July 1991 to $0.56 \pm 0.12 \mu \mathrm{m}$ in August-September 


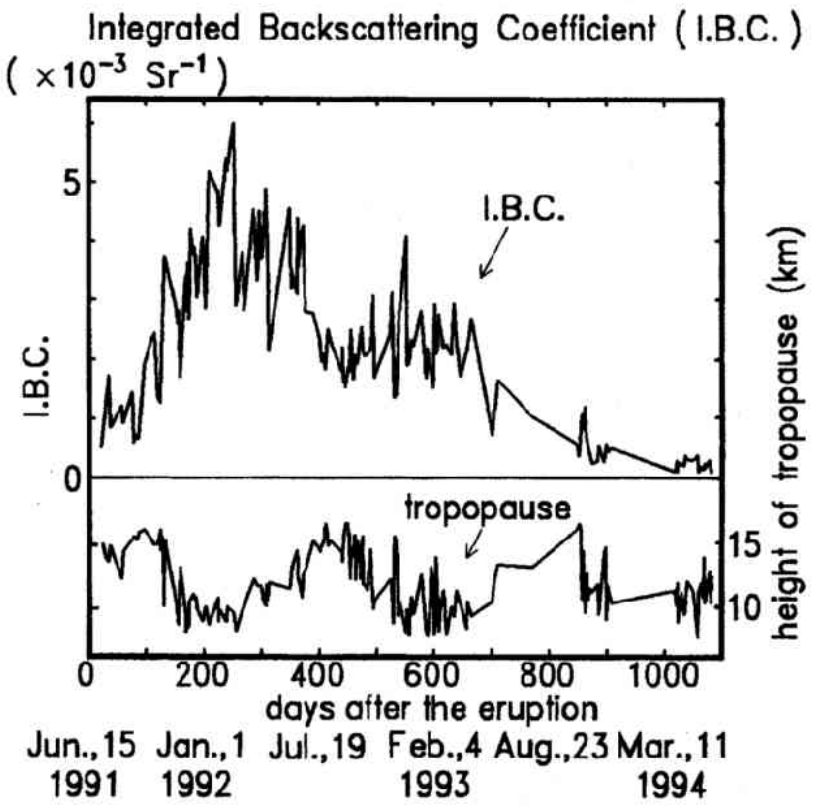

Fig. 8. Variation of Integrated Backscattering Coefficient (I.B.C.) and tropopause height.

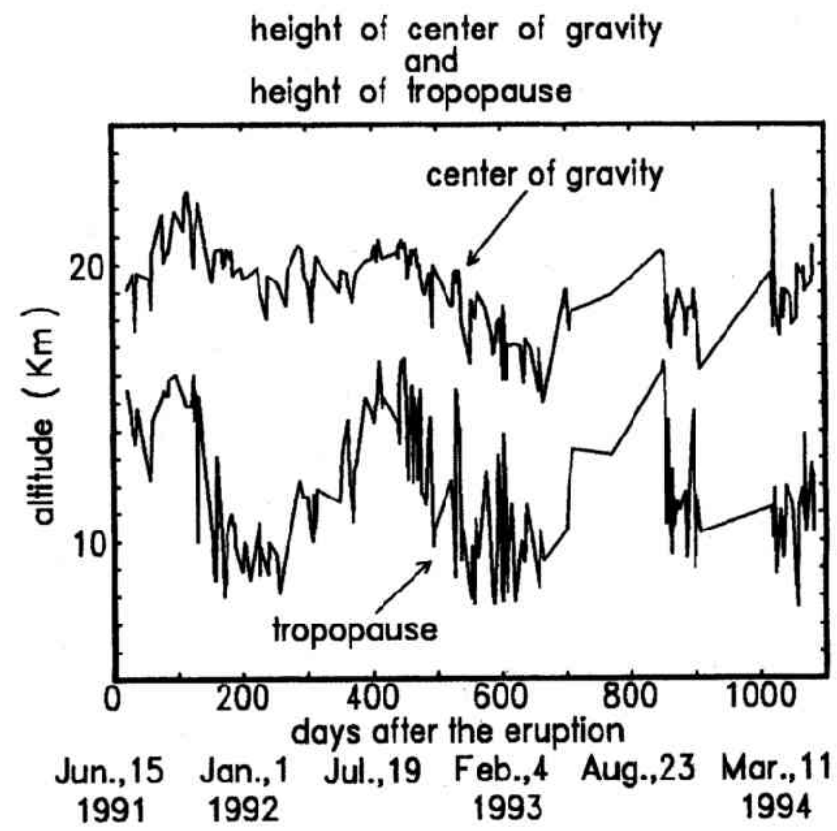

Fig. 9. Variation of center of gravity of backscattering coefficient and tropopause height.

1991 and to $0.86 \pm 0.29 \mu \mathrm{m}$ in July 1992 . While, Pueschel et al. (1994) collected the samples of the volcanic aerosols by airborne instruments and reported that there were three modes of the particle radius in the lower stratosphere. That is, model with the radius of $0.10 \pm 0.04 \mu \mathrm{m}$, mode 2 with the radius of 0.33 $\pm 0.09 \mu \mathrm{m}$, and mode 3 with the radius of $0.60 \pm 0.10$. And they emphasized that large-particle mode with 
a geometric mean radius of $0.4 \mu \mathrm{m}$ was enhanced in the lower stratosphere after the eruption of Mt. Pinatubo. Our result is not contradictory to those results, but is a little under estimated. That is due to the under estimate of the settling velocity, which is calculated from the altitudes of the center of gravity in the same season of the first year and the second year. The average velocity is not the actual settling velocity but lower limit of the settling velocity, because there is a possibility that the center of gravity might have settled to the equilibrium height in a period shorter than one year. Although it is not possible to estimate the particle radius precisely only by our data, our result is enough to emphasize the enhancement of larger particles after the eruption of Mt. Pinatubo.

Figure 3(d) is one of the vertical profiles of scattering ratios observed in the third year. The values were quite small compared to the values observed in the first year. Since the third year, scattering ratios have never exceeded the value of 2 .

The authors thank Mr. K. Susumu and Mr. Y. Nakura for their assistance in the lidar operations. The authors greatly appreciate Fukuoka Meteorological Observatory for providing us rawin sonde sounding data, and Meteorological Research Institute for providing us the information about the optical properties of Mt. Pinatubo aerosols.

The Editor thanks T. Yamazaki and another referee for their assistance in evaluating this paper.

\section{REFERENCES}

Bluth, G. J. S., S. D. Doiron, C. C. Schnetzler, A. J. Krueger, and L. S. Walter, Global tracking of the $\mathrm{SO}_{2}$ clouds from the June, 1991 Mount Pinatubo eruptions, Geophys. Res. Lett., 19, 151-154, 1992.

DeFoor, T. E., E. Robinson, and S. Ryan, Early lidar observations of the June 1991 Pinatubo eruption plume at Mauna Loa Observatory, Hawaii, Geophys. Res. Lett., 19, 187-190, 1992.

Fernald, F. G., Analysis of atmospheric lidar observations: Some comments, Appl. Opt., 23, 652-653, 1984.

Gobbi, G. P., F. Congeduti, and A. Adriani, Early stratospheric effects of the Pinatubo eruption, Geophys. Res. Lett., 19, 997$1000,1992$.

Hayashida, S. and Y. Sasano, Stratospheric aerosol change in the early stage of volcanic disturbance by the Pinatubo eruption observed over Tsukuba, Japan, Geophys. Res. Lett., 20, 575-578, 1993.

Hofmann, D. J. and S. Solomon, Ozone destruction through heterogeneous chemistry following the eruption of El Chichón, J. Geophys. Res., 94, 5029-5041, 1989.

Jăger, H., The Pinatubo eruption cloud observed by lidar at Garmisch-Partenkirchen, Geophys. Res. Lett., 19, 191-194, 1992.

McCormick, M. P. and R. E. Veiga, SAGE II measurements of early Pinatubo aerosols, Geophys. Res. Lett., 19, 155-158, 1992.

McPeters, R. D., The atmospheric $\mathrm{SO}_{2}$ budget for Pinatubo derived from NOAA-11 SBW/2 spectral data, Geophys. Res. Lett., 20, 1971-1974, 1993.

Pueschel, R. F., P. B. Russell, D. A. Allen, G. V. Ferry, K. G. Snetsinger, J. M. Livingston, and S. Verma, Physical and optical properties of the Pinatubo volcanic aerosol: Aircraft observations with impactors and a Sun-tracking photometer, J. Geophys. Res., 99, 12915-12922, 1994.

Russell, P. B., J. M. Livingston, E. G. Dutton, R. F. Pueschel, J. A. Reagan, T. E. DeFoor, M. A. Box, D. Allen, P. Pilewskie, B. M. Herman, S. A. Kinne, and D. J. Hofmann, Pinatubo and pre-Pinatubo optical-depth spectra: Mauna Loa measurements, comparisons, inferred particle size distributions, radiative effects, and relationship to lidar data, J. Geophys. Res., 98, 22,969$22,985,1993$.

Strong, A. E. and L. L. Stowe, Comparing stratospheric aerosols from El Chichón and Mount Pinatubo using AVHRR data, Geophys. Res. Lett, 20, 1183-1186, 1993.

Uchino, O., T. Nagai, T. Fujimoto, M. Fujiwara, H. Akiyoshi, S. Yasumatsu, S. Hayashida, Y. Sasano, H. Nakane, Y. Iwasaka, M. Nagatani, T. Shibata, T. Itabe, K. Asai, A. Nomura, Y. Saito, T. Kano, Y. Sai, K. Tamaki, R. Nomura, T. Sunagawa, C. Nagasawa, M. Abo, Y. Idesako, and K. Kai, Observation of Pinatubo volcanic cloud by lidar network in Japan, J. Meteor. Soc. Japan, 71, 285-295, 1993.

Uchino, O., T. Nagai, T. Fujimoto, W. A. Matthews, and J. Orange, Extensive lidar observations of the Pinatubo aerosol layers at Tsukuba $\left(36.1^{\circ} \mathrm{N}\right)$, Naha $\left(26.2^{\circ} \mathrm{N}\right)$, Japan and Lauder $\left(45.0^{\circ} \mathrm{S}\right)$, New Zealand, Geophys. Res. Lett., 22, 57-60, 1995.

Xue Xi Tie, Guy P. Brasseue, Bruce Briegleb, and Claire, Two dimensional simulation of Pinatubo aerosol and its effect on stratospheric ozone, J. Geophys. Res., 99, 20545-20562, 1994. 